\title{
In vitro anthelmintic activity of Combretum molle (R. Br. ex G. Don) (Combretaceae) against Haemonchus contortus ova and larvae
}

\author{
I.O. Ademola ${ }^{a, b}$ and J.N. Eloff ${ }^{a}$ \\ a Phytomedicine Programme, Department of Paraclinical Sciences, Faculty of Veterinary Science, \\ University of Pretoria, Onderstepoort 0110, South Africa \\ b Department of Veterinary Microbiology and Parasitology, Faculty of Veterinary Medicine, University of \\ Ibadan, Ibadan, Nigeria
}

\begin{abstract}
Parasitic nematodes, especially Haemonchus contortus (Rudolphi), are among the most common and economically important causes of disease in sheep and goats owned by pastoralists and small holder farmers in Africa. The control of these infections relies mainly on the use of anthelmintic drugs. However, herbal preparations are widely used by pastoralists and small holder farmers for the treatment of their livestock against helminth parasites. The anthelmintic effect of acetone leaf extract and fractions of Combretum molle was investigated to determine the relative efficacy of the components against gastrointestinal sheep nematodes. The fractions were obtained by solvent:solvent extraction from the acetone extract. These were evaluated for nematocidal activity by means of an egg hatch (EHA) and larval a development and viability assay (LDVA) in vitro. The effect of the test extracts on the hatchability of eggs and development of first to third stage larvae and the survival rate of the third stage larvae. H. contortus, were used to determine the relative bioactivities. Best-fit $\mathrm{LC}_{50}$ values were computed using global model of nonlinear regression curve-fitting. The extracts inhibited egg hatching and development of the larvae of $H$. contortus in a concentration-dependent manner. Best-fit $\mathrm{LC}_{50}$ values for the egg hatch test were $0.866,0.333,0.833,0.747$, and $0.065 \mathrm{mg} / \mathrm{mL}$ for acetone extract, $\mathrm{n}$-butanol, hexane, chloroform, and 35\% water in methanol fractions, respectively. The best-fit $\mathrm{LC}_{50}$ values for the LDVA were $0.604,0.362,1.077,0.131$ and $0.318 \mathrm{mg} / \mathrm{mL}$ for the acetone extract, butanol, hexane, chloroform, and 35\% water in methanol fractions, respectively. In the EHA the 35\% water in methanol fraction was significantly more active than all the other fractions $(p<0.05)$;
\end{abstract}


however the activity was not significantly different with the LDVA. C. molle leaf could find application in anthelmintic therapy in veterinary practice.

Keywords: Anthelmintic activity; Combretum molle; Haemonchus contortus; Solvent:solvent fractions

\section{Introduction}

Gastrointestinal parasites are of major economic importance in livestock because they cause clinical and sub clinical infections that reduce animal survival and depress growth rates, wool and milk production, and reproductive performance. Animal deaths due to nematode infections are very common in tropical and subtropical regions, where marginal levels of nutrition exacerbate the detrimental effects of infection (Waller, 1997). Control programs based solely on the use of synthetic anthelmintics are no longer considered sustainable because of an increased prevalence of gastointestinal nematode resistance (Barry and Mc Nabb, 1999), the slow development of new anthelmintics, high costs to poor farmers and concerns regarding residue in food and the environment. Alternative methods of control are thus required that are both practical and realistic for introduction into farm production systems.

Traditional health practitioners in many parts of Africa usually employ the leaves and barks of Combretum species as remedies for a variety of human ailments, including abdominal discomfort, body pains, respiratory disorders, colds and fevers, ear and eye ailments, schistosomiasis, hookworms, dysmenorrhoea and infertility in women, leprosy, syphilis, microbial infections and general body weakness (Hutchings et al., 1996). It is regarded as a medicine for both humans and animals. The leaves of Combretum molle contain steroidal acids and saponins (Pegel and Rogers, 1985). Many triterpenoids and their glycosides have been isolated from the leaves of South African Combretum species (Pegel and Rogers, 1985 and Rogers and Verotta, 1996).

The aim of this study was to investigate the anthelmintic effect of acetone leaf extract and fractions of C. molle and the relative efficacy of the components against gastrointestinal sheep nematodes. 


\section{Materials and methods}

\subsection{Preparation plant extracts}

The leaf of the plant C. molle was collected in Zaria, Nigeria. Voucher specimens (No. 900191) were identified and deposited by the Herbarium Section of the Biological Sciences Department, Ahmadu Bello University, Zaria. The plant material was air dried and ground to a powder (170 g) using a Macsalab Model 200 LAB grinder. The extract was prepared by maceration with shaking (Labotec Model 20.2 shaker) for $24 \mathrm{~h}$ in 70\% acetone (A) with a 10:1 solvent to dry weight ratio (Eloff, 1998) and the extract was filtered through Whatman No. 1 filter paper using a Buchner funnel, and the acetone removed by air drying. A solvent:solvent group separation procedure used by the USA National Cancer Institute as described by Suffness and Douros (1979) was adopted to fractionate the acetone extract with a slight variation. The acetone extract $(15.80 \mathrm{~g})$ was dried in a rotary evaporator under reduced pressure and this extract was dissolved in a 1:1 mixture of chloroform and water. The water fraction was extracted with an equal volume of butanol in a separating funnel to yield the water and butanol fractions. The chloroform fraction was dried in a rotary evaporator under reduced pressure and extracted with a 1:1 mixture of hexane and 10\% water in methanol. The hexane fraction was recovered with a separating funnel. The $10 \%$ water in methanol extract was diluted to $35 \%$ water in methanol and extracted by adding equal volume of chloroform to yield the chloroform fraction and the $35 \%$ water in methanol fractions.

\subsection{Haemonchus contortus egg recovery}

H. contortus eggs were recovered from faeces according to Hubert and Kerboeuf (1992). Sample

of faeces (10-15 g) were collected from sheep experimentally infected with mono-specific larval suspensions of fresh $H$. contortus. The faecal samples were suspended in water and cleared of organic debris by filtration through $1 \mathrm{~mm}$ and $150 \mu \mathrm{m}$ sieves. Eggs were collected on a $25 \mu \mathrm{m}$ sieve and further cleared of organic debris by centrifugation in magnesium sulphate (density 1.10) for five minutes at $1000 \times g$. The supernatant was filtered through $100 \mu \mathrm{m}$ and $63 \mu \mathrm{m}$ sieves and the eggs were washed in water and collected on a $25 \mu \mathrm{m}$ sieve. The concentration of eggs was estimated in $200 \mu \mathrm{L}$ samples and adjusted to 500 eggs $/ \mathrm{mL}$. $5 \mu \mathrm{g} / \mathrm{mL}$ amphotericin B solution (Sigma, Germany) was added to the egg suspension to avoid fungal development. 


\subsection{Egg hatch assay}

The in vitro egg hatch assay was based on the method described by Coles et al. (1992). Egg suspension $(0.2 \mathrm{~mL})$ was distributed in a 48 -flat-bottomed microplate so that each well contain 100 fresh eggs and mixed with the same volume of plant extract dissolved in acetone at concentrations of $10 \mathrm{mg} / \mathrm{mL}$ in 8 serial dilutions. Albendazole ( $99.8 \%$ pure standard reference) (Sigma, USA) was used as a positive control. The albendazole was dissolved in dimethyl sulfoxide (DMSO) and diluted at concentrations between $1 \mu \mathrm{g} / \mathrm{mL}$ and $0.0075 \mu \mathrm{g} / \mathrm{mL}$. The control plates contained the diluents water and acetone or $0.3 \%$ DMSO and the egg solution. The eggs were incubated in this mixture for $48 \mathrm{~h}$ at $27^{\circ} \mathrm{C}$ and $70 \%$ relative humidity. After this time a drop of Lugol's iodine solution (Reidel de Hae, Germany) was added to stop the eggs from hatching. All the eggs and first-stage larvae $\left(\mathrm{L}_{1}\right)$ in each plate were counted. There were three replicates for each concentration and control.

\subsection{Larval development and viability assay}

The procedures used were a modification of the technique described by Hubert and Kerboeuf (1992). $150 \mu \mathrm{L}$ aliquots of egg suspension which contained approximately 100 eggs and $20 \mu \mathrm{L}$ of filtrate obtained by faecal washing during egg recovering were distributed to wells of a 48well flat-bottomed microtiter plate. This suspension was supplemented with $30 \mu \mathrm{L}$ of the nutritive medium described by Hubert and Kerboeuf (1984) and comprised of Earle's balanced salt solution (Sigma, Germany) plus yeast extract (Sigma, Germany) in saline solution (1 g of yeast extract $/ 90 \mathrm{~mL}$ of saline solution) at a ratio of $1: 9(\mathrm{v} / \mathrm{v})$. The plates were incubated at $27^{\circ} \mathrm{C}$ and $70 \%$ relative humidity. After 48 h, $200 \mu \mathrm{L}$ of the extract, albendazole (Sigma, USA) or diluent (control) were added. The third stage larvae were recovered six days later. At this time the parasites were counted by separating the larvae into two classes, third-stage larvae $\left(\mathrm{L}_{3}\right)$ and other developmental stage larvae $\left(\mathrm{L}_{1}\right.$ and $\left.\mathrm{L}_{2}\right)$. There were three replicates for each concentration and control.

\subsection{Statistical analysis}

The $\mathrm{LC}_{50}$ was determined by calculating the concentration of extract that gave a response halfway between the minimum and maximum responses in a concentration-response sigmoid curve. The relation below gives the egg hatch and larval viability parameter respectively: 


\section{Number of larqae /botal number of lartae end cgge \\ in uedls with plant extract}

\section{Number of larvas total number of lavas and egss in eontrol Fell [ water?}

\section{Number of larwate LS 3 total number of nematorle in wells with plant ex tract.}

\section{Number of larvae L3/ total number of nematoxde in eonhol well (usger)}

Determination of $\mathrm{LC}_{50}$ of a sigmoidal concentration response (variable slope) curve was performed using GraphPad Prism version 4.01 for Windows (GraphPad, San Diego, CA, USA).

The analysis of the family of data sets generated by four solvent:solvent fractions tested was performed by the global curve-fitting model of nonlinear regression analysis with top and bottom shared among the data sets. In addition, the bottom of the curve was constrained as $>0$ and the top was constrained as $<1.0$. A (global) best-fit value that applies to the family of data sets was calculated for each of these shared parameters, while the best-fit $\mathrm{LC}_{50}$ value (unshared parameter) was calculated with a 95\% confidence interval for each of the data sets (fractions). The relative bioactivities of the fractions was further assessed by comparing the best-fit $\mathrm{LC}_{50}$ value of the various fractions by one-way ANOVA and Tukey's multiple comparison test, which was performed using GraphPad Prism version 4.01 for Windows (Ademola et al., 2005).

\section{Results}

\subsection{Yields of extracts and fractions}

The acetone extract gave a yield of $20.23 \mathrm{~g}(11.90 \%$, w/w), whereas the hexane, chloroform, butanol and 35\% water in methanol fractions of the acetone extract gave yields of $6.01 \mathrm{~g}$ (38.05\%), $6.00 \mathrm{~g}(38.04 \%), 1.08 \mathrm{~g}(6.86 \%)$ and $1.28 \mathrm{~g}(8.11 \%)$, respectively. The water fraction was contaminated with fungi while drying, and was therefore excluded from the study.

\subsection{Egg hatch assay}

C. molle acetone extract and its fractions inhibited hatching of eggs in a concentration-dependent manner (Fig. 1). The shared statistical parameters of the curve fitting analysis and the best-fit $\mathrm{LC}_{50}$ values for the acetone extract and its fractions are shown in Table 1. Tukey's multiple 
comparison (post-ANOVA) test shows that the chloroform fraction is significantly more active than all the other fractions $(p<0.05)$ Table 2 . Albendazole produced an $\mathrm{LC}_{50}$ for egg the hatch inhibition assay at a low concentration $(0.164 \mu \mathrm{g} / \mathrm{mL})$, indicating that the strain of $H$. contortus used in the current study was susceptibility.
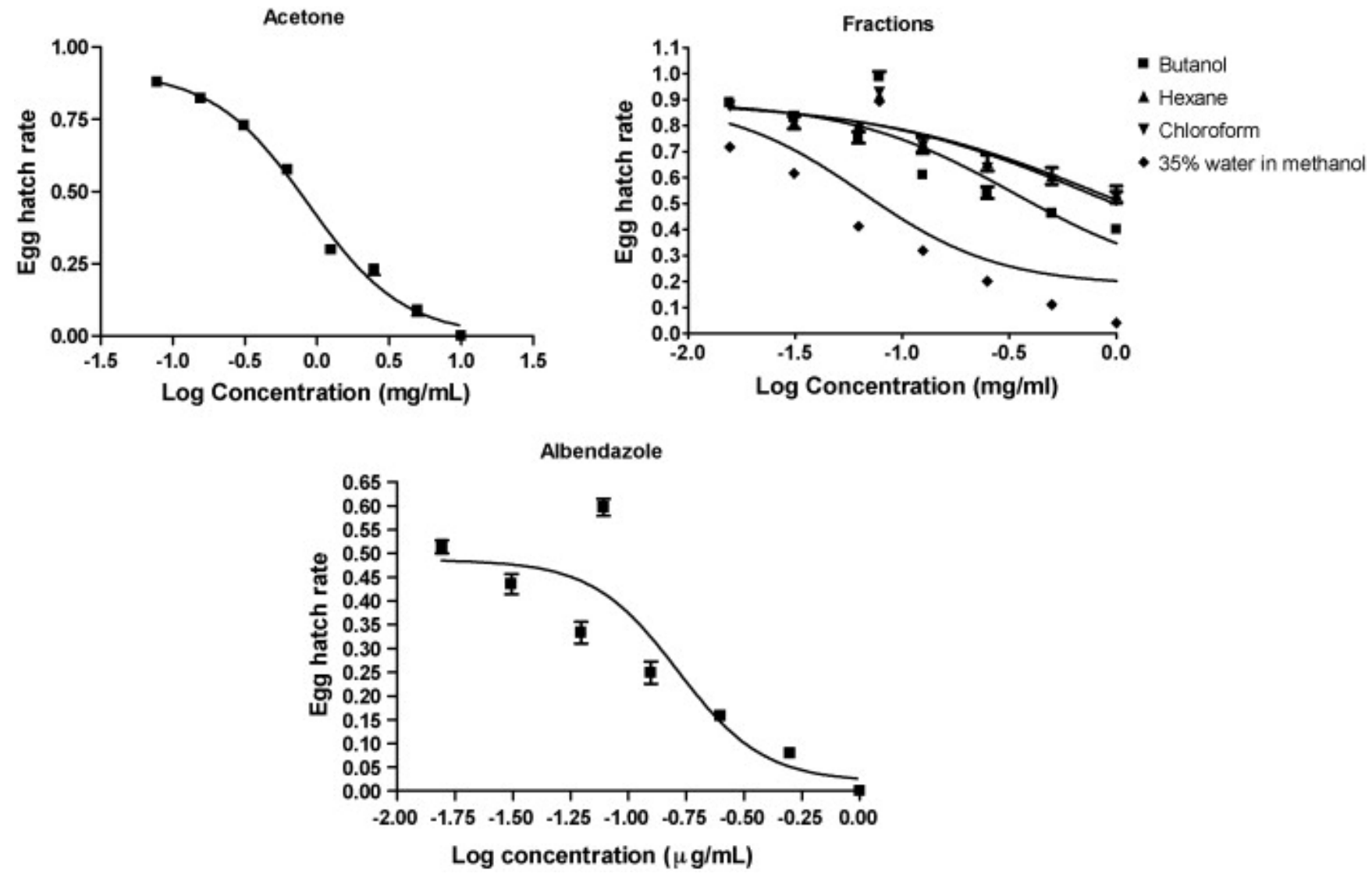

Fig. 1. Egg hatch assay concentration-response curve of acetone extract and fractions of $C$. molle, and albendazole against eggs of $\mathrm{H}$. contortus using global sigmoidal model of curve fitting. 
Table 1: Egg hatch assay $L_{50}$ of C. molle acetone extract and its fractions using global sigmoidal (four-parameter logistic) model of curve-fitting.

\begin{tabular}{|l|l|l|l|l|l|}
\hline Fractions & \multicolumn{2}{|l|}{ log LC } & \multicolumn{2}{l|}{ LC $_{50}(\mathbf{m g} / \mathbf{m L})^{\mathbf{a}}$} & $R^{2}$ \\
\hline & Best-fit & Std. error & Best-fit & $\mathbf{9 5 \%}$ CI & \\
\hline Acetone & -0.0624 & 0.03771 & 0.8661 & $0.7226-1.038$ & 0.9878 \\
\hline Butanol & -0.4770 & 0.1256 & 0.3334 & $0.1874-0.5932$ & 0.7866 \\
\hline Hexane & -0.0803 & 0.1773 & 0.8311 & $0.3686-1.874$ & 0.7942 \\
\hline Chloroform & -0.1267 & 0.1668 & 0.7470 & $0.3477-1.605$ & 0.8127 \\
\hline 35\% water in methanol & -1.182 & 0.1010 & 0.06576 & $0.04138-0.1045$ & 0.6204 \\
\hline Albendazole & -0.7865 & 0.09927 & $0.1635^{b}$ & $0.1015-0.2634$ & 0.8157 \\
\hline
\end{tabular}

${ }^{a}$ Global shared parameters for acetone extract and fractions.

${ }^{\mathrm{b}} \mu \mathrm{g} / \mathrm{mL}$.

Table 2: Tukey's multiple comparison test comparing the $L C_{50}$ values of fractions of C. molle.

\begin{tabular}{|l|l|l|l|}
\hline \multicolumn{2}{|l|}{ Egg hatch assay } & Larval dev. and viability assay \\
\hline Comparisons & $p$-Value & Comparisons & $p$-Value \\
\hline Butanol vs hexane & $p>0.05$ & Hexane vs 35\% water in methanol & $p>0.05$ \\
\hline Butanol vs chloroform & $p>0.05$ & Hexane vs butanol & $p>0.05$ \\
\hline Butanol vs 35\% water in methanol & $p>0.05$ & Hexane vs chloroform & $p>0.05$ \\
\hline Hexane vs chloroform & $p>0.05$ & $35 \%$ water in methanol vs butanol & $p>0.05$ \\
\hline Hexane vs 35\% water in methanol & $p<0.05$ & $35 \%$ water in methanol vs chloroform & $p>0.05$ \\
\hline Chloroform vs 35\% water in methanol & $p<0.05$ & Butanol vs chloroform & $p>0.05$ \\
\hline
\end{tabular}




\subsection{Larval development and viability assay}

The C. molle extracts killed the nematode larvae in a concentration-dependent manner (Fig. 2).

The shared statistical parameters of the curve fitting analysis and the best-fit $\mathrm{LC}_{50}$ values for the acetone extract and the fractions are shown in Table 3. There was no significant difference in the activity of the fractions on the larvae $(p>0.05)$. Albendazole produced an $\mathrm{LC}_{50}$ at a low concentration $(0.144 \mu \mathrm{g} / \mathrm{mL})$, indicating that the strain of $H$. contortus used in the current study was susceptible.
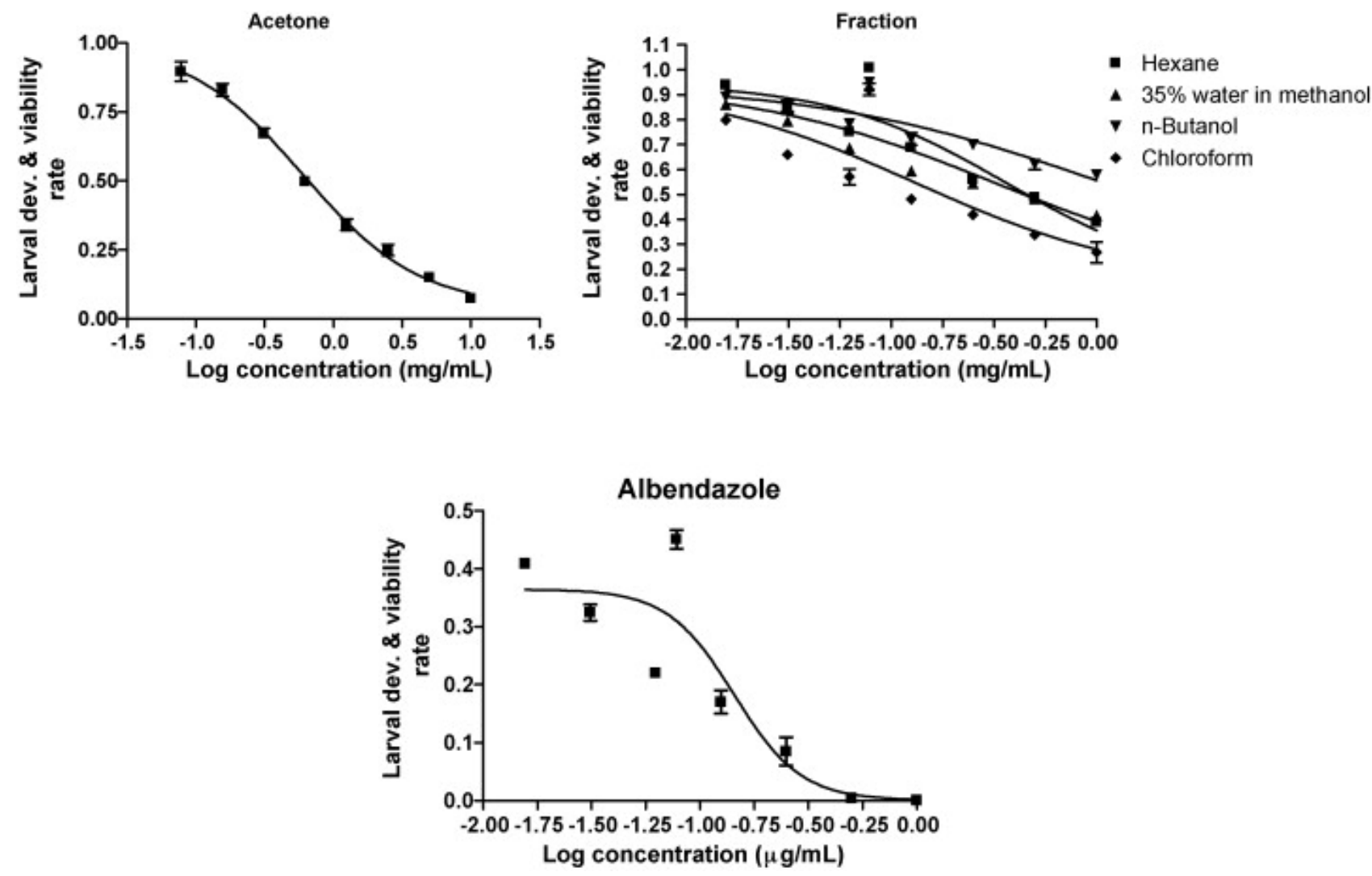

Fig. 2. Larval development and viability assay concentration-response curve of acetone extract and fractions of $C$. molle, and albendazole against larvae of $\mathrm{H}$. contortus using global sigmoidal model of curve fitting. 
Table 3: Larval development and viability assay $L C_{50}$ of C. molle acetone extract and its fractions using global sigmoidal (four-parameter logistic) model of curve-fitting.

\begin{tabular}{|l|l|l|l|l|l|}
\hline Fractions & \multicolumn{2}{|l|}{ log LC } & \multicolumn{2}{l|}{ LC $_{\mathbf{5 0}}(\mathbf{m g} / \mathbf{m L})^{\mathbf{a}}$} & $R^{2}$ \\
\hline & Best-fit & Std. error & Best-fit & $\mathbf{9 5 \%}$ CI & \\
\hline Acetone & -0.2192 & 0.05611 & 0.6037 & $0.4611-0.7904$ & 0.9872 \\
\hline Butanol & -0.4418 & 0.3175 & 0.3616 & $0.1417-0.9226$ & 0.8264 \\
\hline Hexane & 0.03218 & 0.2043 & 1.077 & $0.2511-4.619$ & 0.7512 \\
\hline Chloroform & -0.8832 & 0.2659 & 0.1308 & $0.03866-0.4429$ & 0.6785 \\
\hline 35\% water in methanol & -0.4970 & 0.2750 & 0.3184 & $0.09023-1.124$ & 0.7631 \\
\hline Albendazole & -0.8422 & 0.08774 & $0.1438^{b}$ & $0.09436-0.2192$ & 0.8076 \\
\hline
\end{tabular}

${ }^{\mathrm{a}}$ Global shared parameters for acetone extract and fractions.

${ }^{\mathrm{b}} \mu \mathrm{g} / \mathrm{mL}$.

\section{Discussion}

The problem of anthelmintic resistance in nematodes and an increasing concern over the presence of drug residues in animal products, when pure compounds are administered, has led to a resurgence of interest in the use of phytomedicines, in the form of extracts containing a mixture of compounds (Athanasiadou et al., 2001).

The $\mathrm{LC}_{50}$ values for the hexane and chloroform fractions for egg hatch inhibition were close to each other (Table 1), which explains why only three distinct curves are seen in Fig. 1. The acetone extract and solvent:solvent fractions affected the hatchability of $H$. contortus eggs in a concentration-dependent manner. The $\mathrm{LC}_{50}$ obtained for $C$. molle acetone extract was $0.866 \mathrm{mg} / \mathrm{mL}$. On the other hand, the solvent:solvent fractions of C. molle were more potent. The $35 \%$ water in methanol fraction gave the lowest $\mathrm{LC}_{50}$, which is about one-tenth of the value obtained for the hexane fraction which had the highest $\mathrm{LC}_{50}$ and suggest a significant difference $(p<0.05)$. The LDVA results suggest that the $C$. molle extracts affected the larval development from $\mathrm{L}_{1}$ to the infective stage $\left(\mathrm{L}_{3}\right)$ in a concentration-dependent manner. The $\mathrm{LC}_{50}$ value obtained for the C. molle acetone extract was $0.604 \mathrm{mg} / \mathrm{mL}$. On the other hand, the 
solvent:solvent fractions of $C$. molle were more active except for the hexane fraction which had a higher $\mathrm{LC}_{50}(1.077 \mathrm{mg} / \mathrm{mL})$ than the acetone extract. The statistical comparisons made by the one-way ANOVA were computed with associated standard error from the curve-fitting analysis and suggested absence of significant difference $(p>0.05)$. The in vitro activity of pure anthelmintic compounds is usually higher. The $\mathrm{LC}_{50}$ values for albendazole were $0.164 \mu \mathrm{g} / \mathrm{mL}$ and $0.144 \mu \mathrm{g} / \mathrm{mL}$ for EHA and LDVA, respectively. However, there was no anthelmintic activity with aqueous extract of C. molle at $0.5 \mathrm{mg} / \mathrm{mL}$ and $1 \mathrm{mg} / \mathrm{mL}$, when tested on Caenorhabditis elegans (McGaw et al., 2001). Each fraction represents a mixture of chemical compounds with similarity in chemical structure or other physicochemical properties. According to Eloff (1998) acetone dissolves many hydrophilic and lipophylic components from Combretum erythrophyllum and the antimicrobial components in the plant are more lipophylic. It could be that the polar constituents of the plant were responsible for the anthelmintic activity observed in the present study.

The anthelmintic effect of C. molle against nematode may be attributed to its saponin (Mc Allister et al., 2001). Monodesmoside saponins destabilize membranes and increase cell permeability by combining with membrane-associated sterols (Price et al., 1987 and Gee and Johnson, 1988). Other plant extracts with in vitro anthelmintic activity are Peltophorum africanum and Leucaena leucocephala (Bizimenyenra et al., 2006 and Ademola and Idowu, 2006).

\section{Conclusions}

The use of the crude methanol or chloroform extract of the powdered leaf of C. molle may therefore be useful and effective product for the control of gastrointestinal nematode in livestock production. However further spectroscopic studies on the active principles and the development of quality assurance protocols involving the use of reference substance of plant origin for this extract is warranted. Unambiguous structure elucidation of the active principles could provide leads for drug discovery and suitable bioactive marker compounds for standardization of the extract as a phytomedicine. 


\section{Acknowledgements}

The authors are grateful to the National Research foundation South Africa for funding the work. The University of Ibadan, Nigeria is thanked for granting the main author staff development leave. We thank Onderstepoort Veterinary Institute, South Africa and Dr. A.F. Vatta for providing access to facility and technical assistance. The authors are grateful to $\mathrm{F}$. van Schalkwyk, Biozetica Agri-source (Pty) Ltd. Ondersteeport, Pretoria, for providing H. contortus larvae.

\section{References}

Ademola and Idowu, 2006 I.O. Ademola and S.O. Idowu, Anthelmintic activity of Leucaena leucocephala seed extract on Haemonchus contortus infective larvae, Vet. Rec. 158 (2006), pp. $485-486$.

Ademola et al., 2005 I.O. Ademola, A.I. Akanbi and S.O. Idowu, Anthelmintic activity of Leucaena leucocephala chromatographic seed fractions on gastrointestinal sheep nematodes, Pharm. Biol. 45 (7) (2005), pp. 599-604.

Athanasiadou et al., 2001 S. Athanasiadou, I. Kyriazakis, F. Jackson and R.L. Coop, Direct anthelmintic effects of condensed tannins towards different gastrointestinal nematodes of sheep: in vitro and in vivo studies, Vet. Parasitol. 99 (2001), pp. 205-219.

Barry and Mc Nabb, 1999 T.N. Barry and W.C. Mc Nabb, The implication of condensed tannins on the nutritive value of temperate forage fed to ruminant, Br. J. Nutr. 81 (1999), pp. 263-272. Bizimenyenra et al., 2006 E.S. Bizimenyenra, J.B. Githiori, J.N. Eloff and G.E. Swan, In vitro activity of Peltophorum africanum Sond. (Fabaceae) extract on the egg hatching and larval development of the parasitic nematode Trichostrongylus colubriformis, Vet. Parasitol. 142 (2006), pp. 336-343.

Coles et al., 1992 G.C. Coles, C. Bauer, F.H. Borgsteede, S. Geerts, T.R. Klei, M.A. Taylor and P.J. Waller, World Association for the Advancement of Veterinary Parasitology (W.A.A.V.P.) methods for the detection of anthelmintic resistance in nematodes of veterinary importance, Vet. Parasitol. 44 (1992), pp. 35-44.

Eloff, 1998 J.N. Eloff, Which extractant should be used for the screening and isolation of antimicrobial components from plants?, J. Ethnopharmacol. 60 (1998), pp. 1-8. 
Gee and Johnson, 1988 J.M. Gee and I.T. Johnson, Interaction between haemolytic saponins, bile salts and small intestinal mucosa in rat, J. Nutr. 118 (1988), pp. 1391-1397.

Hubert and Kerboeuf, 1984 J. Hubert and D. Kerboeuf, A new method for culture of larvae used in diagnosis of ruminant gastrointestinal strongylosis: comparison with faecal cultures, Can. J. Comp. Med. 48 (1984), pp. 63-71.

Hubert and Kerboeuf, 1992 J. Hubert and D. Kerboeuf, A microlarval development assay for the detection of anthelmintic resistance in sheep nematode, Vet. Rec. 130 (1992), pp. 442-446. Hutchings et al., 1996 A. Hutchings, A.H. Scott, G. Lewis and A.B. Cunningham, Zulu Medicinal Plants - An Inventory, University of Natal Press, Pietermaritzburg, South Africa (1996).

Mc Allister et al., 2001 T.A. Mc Allister, C.B. Annett, C.L. Cockwell, M.E. Olson, Y. Wang and P.R. Cheeke, Studies on the use of Yucca schidigera to control giardiosis, Vet. Parasitol. 97 (2001), pp. 85-99.

McGaw et al., 2001 L.J. McGaw, T. Rabe, S.G. Sparg, A.K. Jager, J.N. Eloff and J. van Staden, An investigation on the biological activity of Combretum species, J. Ethno. 75 (2001), pp. 4550 .

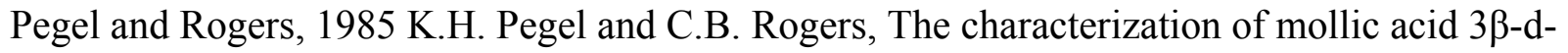
xyloside and its genuine aglycone mollic acid and two novel $1 \alpha$-hydroxycyloartenoids from Combretum molle, J. Chem. Soc. Perkin. Trans. 1 (1985), pp. 1711-1715.

Price et al., 1987 K.R. Price, I.N.T. Johnson and G.R. Fenwick, The chemistry and biological significance of saponins in food and feed stuffs, Res. Food Sci. Nutr. 26 (1987), pp. 27-135.

Rogers and Verotta, 1996 C.B. Rogers and L. Verotta, Chemistry and biological properties of the African Combretaceae. In: K. Hostettmann, F. Chinyanganya, M. Maillard and J.-L. Wolfender, Editors, Chemistry, Biological and Pharmacological Properties of African Medicinal Plants, University of Zimbabwe Publications, Harare (1996), pp. 121-141.

Suffness and Douros, 1979 M. Suffness and J. Douros, Drugs of plant origin, Meth. Canc. Res. 26 (1979), pp. 73-126.

Waller, 1997 P.J. Waller, Sustainable helminth control of ruminants in developing countries, Vet. Parasitol. 71 (1997), pp. 195-207. 